\title{
Overexpression of Tie 2 is associated with poor prognosis in patients with gastric cancer
}

\author{
WEI-JUN YANG ${ }^{1,2}$, YING-XUE HAO ${ }^{1}$, XIA YANG $^{3}$, XIAO-LAN FU $^{3}$, YAN SHI ${ }^{1}$, \\ HAI-LING YUE ${ }^{1}$, PENG YIN ${ }^{1}$, HAO-LIN DONG ${ }^{3}$ and PEI-WU YU ${ }^{1}$ \\ ${ }^{1}$ Department of General Surgery and Center of Minimally Invasive Gastrointestinal Surgery, \\ Southwest Hospital, Third Military Medical University, Chongqing 400038; ${ }^{2}$ Department of \\ General Surgery, The First People's Hospital of Guiyang, Guiyang, Guizhou 550002; \\ ${ }^{3}$ Department of Immunology, Third Military Medical University, Chongqing 400038, P.R. China
}

Received September 24, 2015; Accepted March 14, 2017

DOI: $10.3892 / \mathrm{ol} .2018 .8329$

\begin{abstract}
Tunica Interna endothelial cell kinase (Tie2)-expressing macrophages (TEMs) are a subgroup of tumor-associated macrophages that are associated with a poor prognosis in numerous types of cancer. The present study aimed to assess the prognostic impact of Tie2 expression in gastric cancer tissues. Between January 2009 and December 2009, 76 newly diagnosed patients with gastric cancer at the Southwest Hospital, Third Military Medical University (Chongqing, China) were enrolled. TEMs were detected using immunohistochemistry. Tie2, cluster of differentiation (CD)68 and carbonic anhydrase IX (CAIX) were analyzed using immunohistochemistry and immunofluorescent microscopy. Tie 2 protein expression was analyzed using western blot analysis in hypoxic and normoxic gastric cancer tissues. The number of TEMs positively staining for Tie2 increased with the tumor-node-metastasis (TNM) stage: $0,53.9,75.6$ and $100 \%$ in stages I, II, III and IV, respectively $(\mathrm{P}<0.001)$. Tumor size and lymph node involvement were significantly associated with the presence of Tie2 in the tumor stroma $(\mathrm{P}<0.001)$. There was no significant difference between Tie 2 and CAIX, irrespective of how the patients were grouped (tumor size, lymph node involvement, TNM stage or histological grade). Tie 2 protein expression was increased in the hypoxic regions of gastric tumors.Tie2 and CD68 expression colocalized in hypoxic and normoxic gastric cancer tissues. The 1-, 2- and 3-year recurrence rates of the TEM-positive
\end{abstract}

Correspondence to: Dr Ying-Xue Hao or Dr Pei-Wu Yu, Department of General Surgery and Center of Minimally Invasive Gastrointestinal Surgery, Southwest Hospital, Third Military Medical University, 30 Gaotanyan Street, Shapingba, Chongqing 400038, P.R. China

E-mail: haoyingxue@hotmail.com

E-mail: yupeiwu@sina.com

Key words: Tunica Interna endothelial cell kinase, overexpression, prognosis, gastric cancer group were $31.4,56.9$ and $66.7 \%$, respectively, as compared with 8,28 and 48\%, respectively, for the TEM-negative group $(\mathrm{P}<0.05)$. In the TEM-negative group, 2 patients succumbed to the disease, as compared with 21 patients in the TEM-positive group $(\mathrm{P}<0.05)$. Therefore, high quantities of TEMs, represented by Tie2 expression, in gastric tumors may be associated with poor survival.

\section{Introduction}

Gastric cancer is an important health concern with an age-adjusted incidence rate of 9.7/100,000 males and 4.8/100,000 females in the United States (1), however, this incidence rate is higher in Japan, Finland, Iceland, Brazil, Korea and China (2). Notable risk factors include diet (high salt, low animal fat, high complex carbohydrates, nitrites and red or processed meat), mucosal atrophy, chronic gastritis, smoking and Helicobacter pylori infection $(3,4)$. At presentation, only $40 \%$ of patients with gastric cancer are curable, and the 10 -year cancer-associated survival rate is $51 \%$ when the cardia is not involved (5). Treatment typically consists of a combination of surgery and chemotherapy $(6,7)$.

Macrophages from the peripheral blood that infiltrate tumor tissues are named tumor-associated macrophages (TAMs). TAMs are an important part of solid tumors and have an essential role in tumor progression (8-10). Noy et al (11) have hypothesized that the greater the number of macrophages in the tumor, the more efficient their anti-tumor effect. However, previous studies have also identified that the presence of TAMs is associated with a poor prognosis in a number of malignancies (12-14). Certain characteristics of the TAMs may have a functional role in this effect on tumors.

Tunica Interna endothelial cell kinase (Tie2) is a receptor tyrosine kinase expressed on endothelial cells and hematopoietic stem cells (15). Tie2-expressing macrophages (TEMs) are a subgroup of TAMs, which were initially identified in a mouse breast cancer model (16) and are characterized by high expression levels of the pro-angiogenic receptor Tie2. Venneri et al (17) also identified TEMs in the peripheral blood, where they accounted for 2-7\% of the blood mononuclear cells from healthy donors (17). TEMs were primarily 
located in the hypoxic regions of tumors and may be involved in tumor angiogenesis, thus promoting tumor progression and metastasis (18). Previous studies have demonstrated that the degree of TEM infiltration into tumor hypoxic regions may be an adverse prognostic factor for patients with cancer $(14,19)$; however, a small number of studies $(14,20)$ focused on the effects of Tie 2 on tumor recurrence and disease-free survival.

Therefore, the aim of the present study was to assess the prognostic impact of Tie 2 expression in TEMs identified in patients with gastric cancer. The results of the present study indicate Tie 2 to be a novel prognostic marker for these patients or a potential target for therapy.

\section{Materials and methods}

Patient characteristics. From January 2009 to December 2009, 76 newly diagnosed patients (51 males and 26 females aged 28 to 86 years) with gastric cancer who underwent surgical tumor resection at the Department of Surgery and Center of Minimally Invasive Gastrointestinal Surgery, Southwest Hospital, Third Military Medical University (Chongqing, China) by the same gastrointestinal surgery team were enrolled in the present study. Histopathological diagnosis was performed by an experienced pathologist according to the criteria of the American Joint Commission on Cancer (21). The exclusion criteria included a history of previously treated cancer and preoperative chemotherapy or radiotherapy. All patients received adjuvant oxaliplatin and capecitabine chemotherapy. The current study was approved by the Institutional Review Board of the Southwest Hospital, Third Military Medical University and written informed consent was obtained from all patients.

Data collection. Detailed clinicopathological data was collected from the medical records of each patient, including sex, age, tumor location, tumor diameter and the extent of tumor resection. Follow-up was censored in December 2013 and the collection of subsequent treatment, recurrence and survival status data was completed by this date. Progression-free survival (PFS) was defined as the time interval from diagnosis to first tumor progression, recurrence or metastasis. Overall survival (OS) was measured from diagnosis to the date of mortality or to December 2013.

Immunohistochemistry. Gastric cancer tissues were collected during surgery and fixed in $10 \%$ formalin for $24 \mathrm{~h}$ at $18^{\circ} \mathrm{C}$, prior to paraffin embedding. Paraffin sections ( $4 \mu \mathrm{m}$ thick) of gastric cancer tissues were mounted on silanized slides, dewaxed at $56^{\circ} \mathrm{C}$ for $30 \mathrm{~min}$, deparaffinized with xylene (slices were placed in $>99 \%$ xylene I and xylene II for $5 \mathrm{~min}$ at a time) and rehydrated using ethanol $(100,100,95,85,75$ and $75 \%$ ethanol, $3 \mathrm{~min}$ at room temperature) and washed with PBS for 3 min. Peroxidase activity was quenched with $3 \%$ hydrogen peroxidase at room temperature for $15 \mathrm{~min}$ and non-specific background staining was eliminated using blocking buffer ( $2 \%$ goat serum, $0.2 \%$ Triton $\mathrm{X}-100$ and $0.1 \%$ bovine serum albumin in PBS) at room temperature for $1 \mathrm{~h}$. Primary antibodies against Tie2 (dilution, 1:50; cat no. ab24859; Abcam, Cambridge, UK) or carbonic anhydrase IX (CAIX; dilution, 1:400; cat no. ab107257; Abcam) were applied overnight at $4^{\circ} \mathrm{C}$. Following washing three times in PBS for $3 \mathrm{~min}$, immunodetection was performed using a labeled polymer horseradish peroxidase mouse antibody (cat no. SC-51948; dilution, 1:100; Santa Cruz Biotechnology, Inc., Dallas, TX, USA) incubated for $10 \mathrm{~min}$ at room temperature. Slides were subsequently washed with $\mathrm{dH}_{2} \mathrm{O}$, visualized with 3,3'-diaminobenzidine for $10 \mathrm{~min}$ and counterstained with Mayers hematoxylin. The negative controls were obtained by omitting the primary antibodies.

Slides were evaluated using an Eclipse TE2000-S microscope (Nikon Corporation, Tokyo, Japan) by two independent investigators who were blinded to the clinical outcomes. Images were captured under $x 400$ magnification using Image-Pro Plus v5.0 software (Media Cybernetics, Inc., Rockville, MD, USA). Tie 2 and CAIX expression levels in cancer cells were graded as follows: $-(\leq 10 \%$ of positive cells $),+(20 \%-50 \%$ of positive cells $),++(\geq 50 \%$ of positive cells $)$.

Immunofluorescent staining. Paraffin sections were dewaxed by heating to $56^{\circ} \mathrm{C}$ for $30 \mathrm{~min}$, deparaffinized using xylene I and xylene II for $5 \mathrm{~min}$ at a time and rehydrated using ethanol $(100,100,95,85,75$ and $75 \%$ ethanol, $3 \mathrm{~min}$ at room temperature) and washed with PBS for 3 min. Peroxidase activity was quenched using $3 \%$ hydrogen peroxidase at room temperature for $15 \mathrm{~min}$ and non-specific background staining was eliminated using a blocking buffer ( $2 \%$ goat serum, $0.2 \%$ Triton X-100 and $0.1 \%$ bovine serum albumin in PBS) at room temperature for $1 \mathrm{~h}$. Primary antibodies against Tie2 (dilution, 1:50; cat no. SC-324; Santa Cruz Biotechnology, Inc.) or CD68 (dilution, 1:50; cat no. ab955; Abcam) were applied overnight at $4^{\circ} \mathrm{C}$. Following washing three times with PBS for $10 \mathrm{~min}$, the secondary antibodies were added; donkey anti-Rabbit IgG (Alexa Fluor 647, dilution, 1:50; cat no. A31573, or donkey anti-Mouse IgG Alexa Fluor 488, dilution, 1:50; cat no. A21202s; both Invitrogen; Thermo Fisher Scientific, Inc., Waltham, MA, USA) at $37^{\circ} \mathrm{C}$ for $60 \mathrm{~min}$. Then they were washed 5 times with PBS, for $10 \mathrm{~min}$ each time. DAPI was then added at $37^{\circ} \mathrm{C}$ for $5 \mathrm{~min}$. This was followed by washing 3 times with PBS, for $10 \mathrm{~min}$ each time. The slices were then sealed using glycerin. Slides were viewed at a magnification of $x 400$ using a fluorescence microscope (Eclipse TE2000-S Nikon Corporation) using Image-Pro Plus v5.0 software (Media Cybernetics, Inc.).

Statistical analysis. Continuous data are presented as the mean \pm standard deviation and were analyzed using the Student's t test. Categorical data are presented as frequencies and were analyzed using the Fisher's exact test. Pearsons chi-square test was used to compare the recurrence rate of gastric cancer up to 3 years following surgery. Survival rates were analyzed using the Kaplan-Meier method and the log-rank test. Data analysis was performed using SPSS v.13.0 (SPSS, Inc., Chicago, IL, USA). $\mathrm{P}<0.05$ was considered to indicate a statistically significant difference.

\section{Results}

Characteristics of the patients. Table I presents the characteristics of all enrolled patients. A total of 51 male and 25 female patients were enrolled in the present study. The median age was 56 years (range, 28-86). The tumors were located in the gastric antrum in 42 patients, in the body of the stomach in 16 patients 
Table I. Clinicopathological characteristics of the patients with gastric cancer $(n=76)$.

\begin{tabular}{|c|c|c|}
\hline Characteristic & Tie2-positive, n (\%) & P-value \\
\hline Age, years & & NS \\
\hline$<60$ & $32 / 50(64.0)$ & \\
\hline$\geq 60$ & $19 / 26(73.1)$ & \\
\hline Gender & & NS \\
\hline Male & $34 / 51(66.7)$ & \\
\hline Female & $17 / 25(68.0)$ & \\
\hline Tumor size ${ }^{b}$ & & $<0.001$ \\
\hline $\mathrm{T} 1$ & $0 / 2(0.0)$ & \\
\hline $\mathrm{T} 2$ & $3 / 13(23.1)$ & \\
\hline $\mathrm{T} 3$ & $40 / 53(75.5)$ & \\
\hline $\mathrm{T} 4$ & 8/8 (100.0) & \\
\hline Lymph node metastases ${ }^{c}$ & & $<0.001$ \\
\hline No & 4/17 (23.5) & \\
\hline N1 & $18 / 28(64.3)$ & \\
\hline N2 & 28/30 (93.3) & \\
\hline N3 & 1/1 (100.0) & \\
\hline TNM stage & & $<0.001$ \\
\hline I & $0 / 9(0.0)$ & \\
\hline II & $7 / 13$ (53.9) & \\
\hline III & $31 / 41(75.6)$ & \\
\hline IV & $13 / 13(100.0)$ & \\
\hline Histological grade & & NS \\
\hline I & 9/10 (90.0) & \\
\hline II & $12 / 21(57.1)$ & \\
\hline III & $30 / 45(66.7)$ & \\
\hline Tumor location & & NS \\
\hline Gastric antrum & $26 / 42(61.9)$ & \\
\hline Body of the stomach & $10 / 16(62.5)$ & \\
\hline Cardia & $15 / 18(83.3)$ & \\
\hline
\end{tabular}

${ }^{\mathrm{a}} \mathrm{P}<0.05$. P-values were obtained using the Fisher's exact test. NS, not significant; Tie2, Tunica Interna endothelial cell kinase. ${ }^{\mathrm{b}} \mathrm{T} 1$, The tumor is immersed in the basement membrane or submucosa. T2, The tumor is immersed in the muscle film or subserous membrane. T3, The tumor penetrates the serous membrane but does not infiltrate the adjacent tissue. T4, Tumor infiltration adjacent tissue. ${ }^{\mathrm{c}} \mathrm{N} 0$, No lymph node metastasis. N1, There are 1-6 regional lymph node metastases. $\mathrm{N} 2$, There are 7 to 15 regional lymph node metastases. N3, There are more than 15 regional lymph node metastases.

and in the cardia in 18 patients. The tumor histological grade was I in 10 patients, II in 21 patients and III in 45 patients. The tumor-node-metastasis (TNM) stage (22) was I in 9 patients, II in 13 patients, III in 41 patients and IV in 13 patients. The median follow-up was 52.3 months (range, 48-60) and no patient failed to complete follow-up.

Associations between clinicopathological characteristics and TEM recruitment in the gastric cancer stroma. The associations between certain clinicopathological characteristics and TEM recruitment in gastric cancer stroma are presented in Table I. The positive rate of TEM recruitment in gastric cancer stroma was $67.2 \%$. TEM recruitment increased with TNM stage: 0, 53.9, 75.6 and 100\% in stages I, II, III and IV, respectively $(\mathrm{P}<0.001)$. Tumor size and lymph node involvement were significantly associated with the presence of TEMs in the tumor stroma $(\mathrm{P}<0.001)$. Age, gender, histological grade and tumor location were not significantly associated with the presence of TEMs in the tumor stroma.

Association between clinicopathological characteristics and the expression of CAIX and Tie2 in gastric cancer. CAIX and Tie2 expression levels in gastric cancer cells are presented in Table II and Fig. 1. The expression of CAIX and Tie2 in gastric cancer was positive in $66 / 76$ patients $(86.8 \%)$ for CAIX and in $65 / 76$ patients $(85.5 \%)$ for Tie2. There was no significant difference between the two markers, irrespective of how the patients were grouped (tumor size, lymph node involvement, TNM stage or histological grade).

Tie2 expression level and its association with hypoxia. Table II demonstrates that Tie2 protein expression was increased in the hypoxic regions of gastric tumors. Comparing the expression of Tie 2 and CAIX in gastric cancer tissues, it was identified that the expression of Tie 2 in gastric cancer tissues was consistent with the expression of hypoxia marker CAIX in gastric cancer tissues. Fig. 2 identifies that Tie 2 and CD68 (a macrophage-specific marker) expression colocalizes in gastric cancer tissues. TEMs are a subset of mononuclear macrophages that infiltrate tumor tissues.

Recurrence of gastric cancer. The 1-, 2- and 3-year recurrence rates are presented in Table III. The recurrence rates of the TEM-positive group were $31.4,56.9$ and $66.7 \%$, respectively, compared with 8,28 and $48 \%$, respectively, for the TEM-negative group $(\mathrm{P}<0.05)$. Tie2 patients with positive gastric cancer experienced a significantly lower incidence of tumor recurrence within three years after surgery than those with negative Tie2 expression. ( $\mathrm{P}<0.05$; Fig. 3 ).

\section{Discussion}

The aim of the present study was to assess the prognostic impact of Tie2 expression in TEMs identified in patients with gastric cancer. These results indicated that Tie 2 and CD68 expression colocalizes in gastric cancer tissues. Tie2 positivity increased with TNM stage. Tumor size and lymph node involvement were significantly associated with the presence of TEM recruitment in the tumor stroma. It was identified that there was no significant difference in tumor stage between Tie 2 and CAIX expression, irrespective of how the patients were grouped (tumor size, lymph node involvement, TNM stage or histological grade). Tie 2 protein expression was increased in the hypoxic regions of the gastric tumors. The 1-, 2- and 3-year recurrence rates were increased in the TEM-positive group, as compared with in the TEM-negative group. In the TEM-negative group, the recurrence rate of tumor recurrence within 3 years after surgery was significantly higher than the TEM-positive group.

CAIX expression levels reflect the state of tumor hypoxia, and its expression in solid tumors is an established marker of poor prognosis (23-26). In the present study, CAIX was used to 
Table II. CAIX and Tie2 expression in gastric cancer $(n=76)$.

\begin{tabular}{|c|c|c|c|c|c|c|c|}
\hline \multirow[b]{2}{*}{ Characteristics } & \multicolumn{3}{|c|}{ CAIX, n (\%) } & \multicolumn{3}{|c|}{ Tie2, n (\%) } & \multirow[b]{2}{*}{ P-value } \\
\hline & - & + & ++ & - & + & ++ & \\
\hline Tumor size ${ }^{a}$ & & & & & & & NS \\
\hline $\mathrm{T} 1$ & $2(100.0)$ & 0 & 0 & $2(100.0)$ & 0 & 0 & \\
\hline $\mathrm{T} 2$ & $3(25.0)$ & $8(66.7)$ & $1(8.3)$ & $3(25.0)$ & $9(75.0)$ & 0 & \\
\hline $\mathrm{T} 3$ & $5(9.4)$ & $13(24.5)$ & $35(66.0)$ & $5(9.4)$ & $24(45.3)$ & $24(45.3)$ & \\
\hline $\mathrm{T} 4$ & 0 & 0 & $9(100.0)$ & 0 & $2(22.2)$ & $7(77.8)$ & \\
\hline Lymph nodes ${ }^{\mathrm{b}}$ & & & & & & & NS \\
\hline No & $9(50.0)$ & $6(33.3)$ & $3(16.7)$ & $10(55.6)$ & $6(33.3)$ & $2(11.1)$ & \\
\hline $\mathrm{N} 1$ & $1(3.6)$ & $15(53.6)$ & $12(42.9)$ & $1(3.6)$ & $21(75.0)$ & $6(21.4)$ & \\
\hline $\mathrm{N} 2$ & 0 & $2(8.0)$ & $23(92.0)$ & 0 & $8(32.0)$ & $17(68.0)$ & \\
\hline N3 & 0 & 0 & $5(100.0)$ & 0 & 0 & $5(100.0)$ & \\
\hline TNM stage & & & & & & & NS \\
\hline I & $5(55.5)$ & $4(44.4)$ & 0 & $5(55.5)$ & $4(44.4)$ & 0 & \\
\hline II & $4(33.3)$ & $6(50.0)$ & $2(16.7)$ & $4(33.3)$ & $6(50.0)$ & $2(16.7)$ & \\
\hline III & $1(2.4)$ & $11(26.2)$ & $30(71.4)$ & $1(2.4)$ & $24(57.1)$ & $17(40.5)$ & \\
\hline IV & 0 & 0 & $13(100.0)$ & 0 & $1(7.7)$ & $12(92.3)$ & \\
\hline Histological grade & & & & & & & NS \\
\hline $\mathrm{I}$ & $2(20.0)$ & $2(20.0)$ & $6(60.0)$ & $2(20.0)$ & $2(20.0)$ & $6(60.0)$ & \\
\hline II & $3(14.3)$ & $9(42.9)$ & $9(42.9)$ & $4(19.1)$ & $11(52.4)$ & $6(28.6)$ & \\
\hline III & $5(11.1)$ & $14(31.1)$ & $26(57.8)$ & $5(11.1)$ & $19(42.2)$ & $21(46.7)$ & \\
\hline
\end{tabular}

P-values were obtained using the Fisher's exact test. NS, not significant; Tie2, Tunica Interna endothelial cell kinase; CAIX, carbonic anhydrase IX. ${ }^{\mathrm{a}} \mathrm{T} 1$, The tumor is immersed in the basement membrane or submucosa. T2, The tumor is immersed in the muscle film or subserous membrane. T3, The tumor penetrates the serous membrane but does not infiltrate the adjacent tissue. T4, Tumor infiltration adjacent tissue.

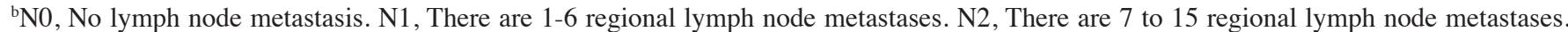
$\mathrm{N} 3$, There are more than 15 regional lymph node metastases.
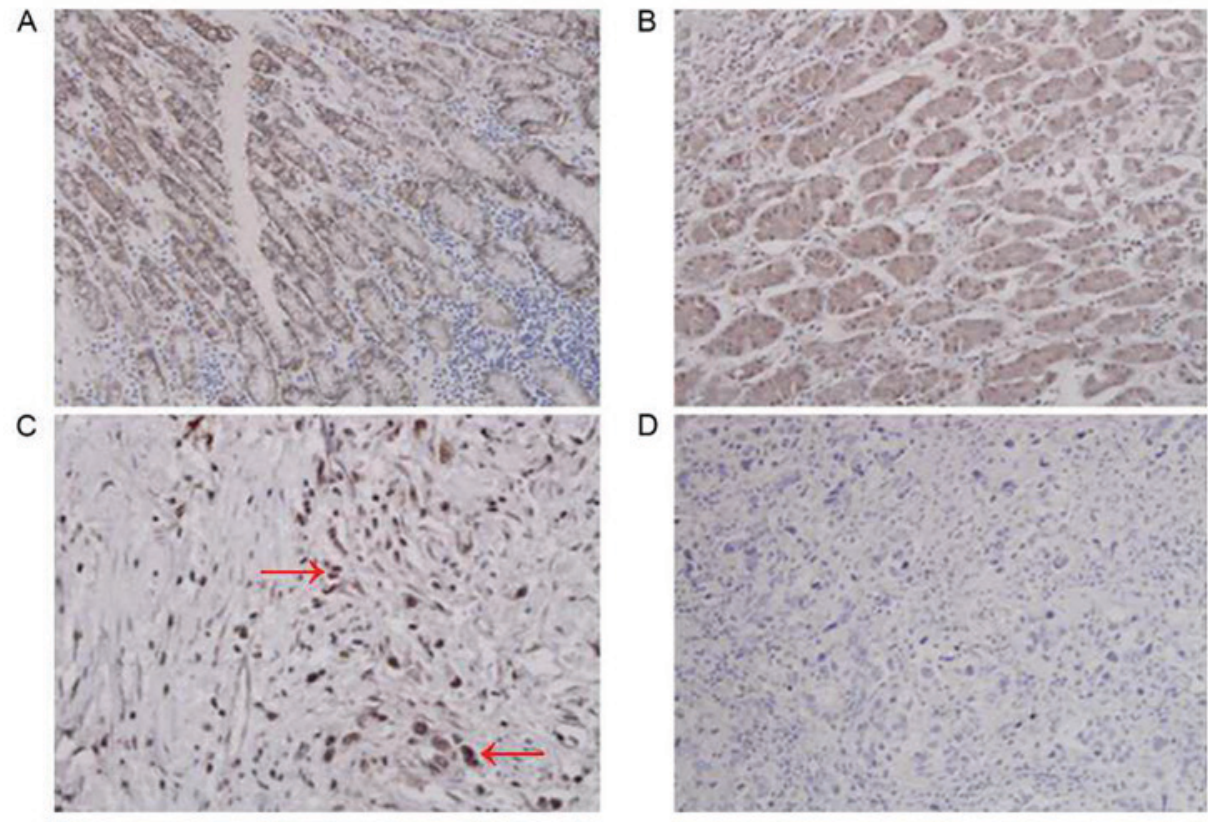

Figure 1. Immunohistochemical examination of human gastric cancer tissues for Tie2 and CAIX. (A) Gastric cancer tissue with positive Tie2 expression. Tie2 was primarily expressed in the gastric cancer cells. Tie2 is mainly expressed in the cytoplasm of macrophages, and the cytoplasm is stained brown and yellow. (B) CAIX positive expression in gastric cancer tissue. CAIX is mainly expressed in the cytoplasm of gastric cancer cells, and the cytoplasm is stained brown and yellow. (C) Numerous Tie2-expressing macrophages were located in the tumor stroma (marked with red arrows). (D) Gastric cancer tissue that is negative for Tie2 expression. Magnification, x400. Tie2, Tunica Interna endothelial cell kinase; CAIX, carbonic anhydrase IX. 
Table III. Tumor recurrence rate of gastric cancer patients within three years of surgery.

\begin{tabular}{lccc}
\hline Recurrence date & TEM-negative, n $(\%)$ & TEM-positive, n $(\%)$ & P-value \\
\hline 1-year & $2 / 25(8.0)$ & $16 / 51(31.4)$ & $0.024^{\mathrm{a}}$ \\
2-year & $7 / 25(28.0)$ & $29 / 51(56.9)$ & $0.018^{\text {a }}$ \\
3-year & $12 / 25(48.0)$ & $34 / 51(66.7)$ & 0.118 \\
\hline
\end{tabular}

${ }^{\text {aP }}<0.05$. P-values were estimated using the Pearson $\chi^{2}$ method. TEM, TEM, Tunica Interna endothelial cell kinase-expressing macrophages.
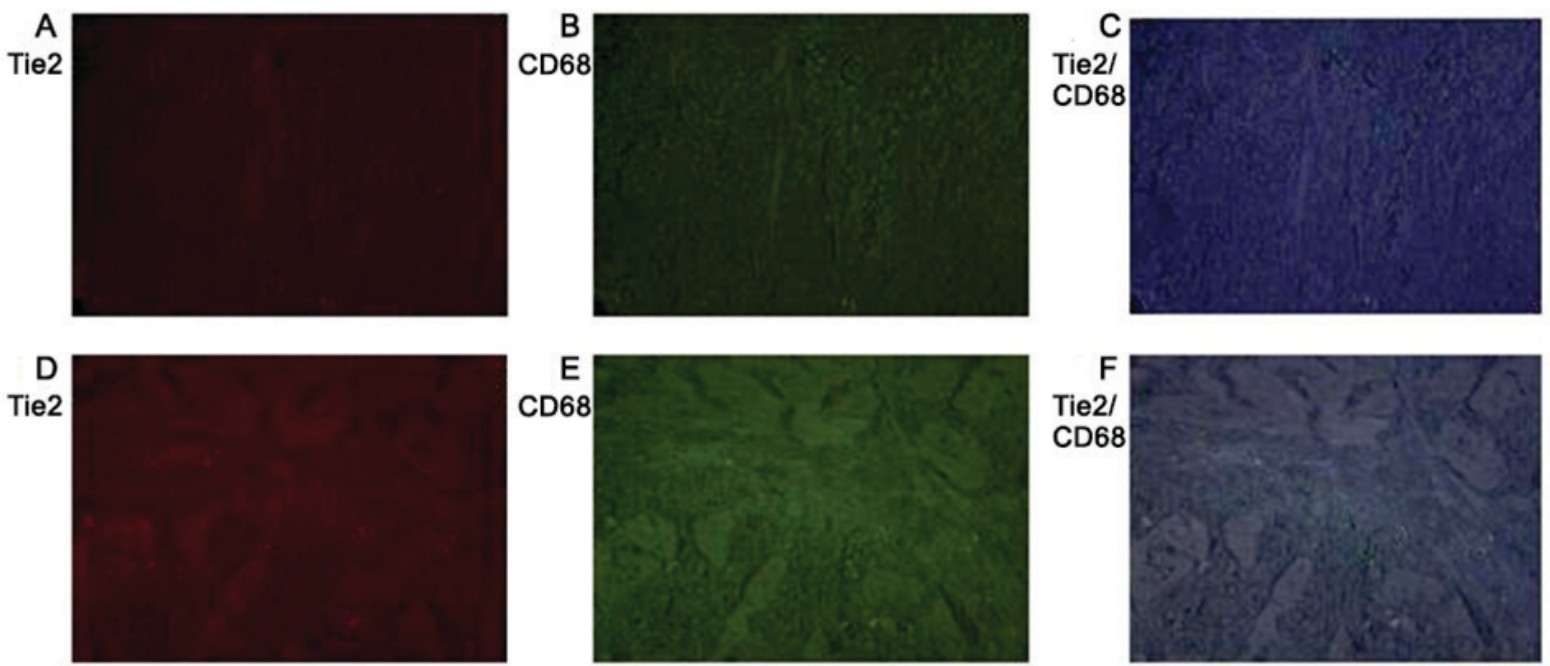

Figure 2. Immunofluorescence analysis for (A) CD68, (B) Tie2 and (C) merged images in hypoxic gastric cancer tissues, and (D) CD68, (E) Tie2 and (F) merged images in normoxic cancer tissues. Magnification, x400. CD68, cluster of differentiation 68; Tie2, Tunica Interna endothelial cell kinase.

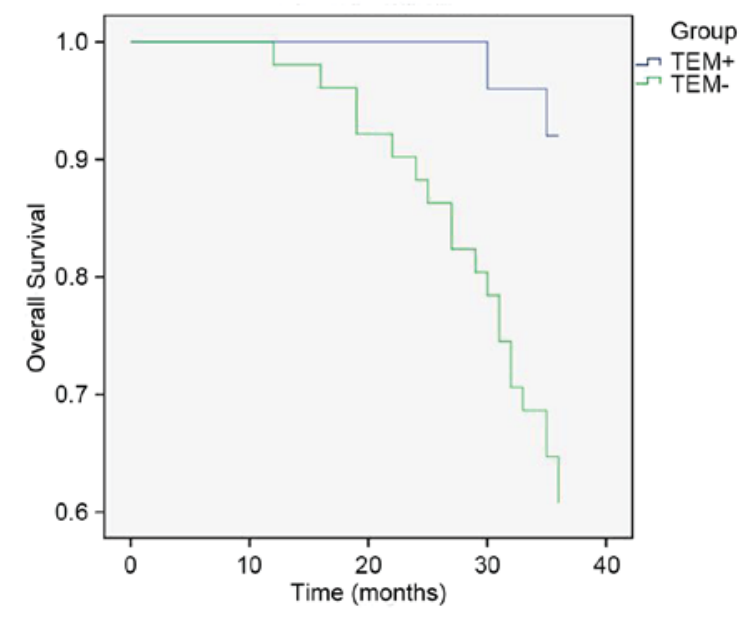

Figure 3. Kaplan-Meier analysis of patient survival rates according to TEM status. Patients with TEM- gastric cancer had a reduced survival rate compared with those with TEM+ cancer. $\mathrm{P}<0.05$, TEM+ vs. TEM-. TEM, Tunica Interna endothelial cell kinase-expressing macrophages.

locate the hypoxic areas in gastric cancer tissues. However, there was no significant difference in the association between CAIX and prognostic markers compared with Tie 2 and prognostic markers, suggesting that CAIX and Tie2 are associated with tumor hypoxia. In addition, western blot analysis demonstrated that Tie2 protein levels are increased in hypoxic tumor tissues.
In the present study, Tie2 immunohistochemistry was used to reflect the infiltration of tumors by TEMs, as TEMs are the only cells known to express Tie2 (17). Positive Tie2 expression was associated with tumor size, lymph node involvement and TNM stage, which are established prognosis markers for gastric cancer (5). Indeed, previous studies have identified that the degree of TEM infiltration of tumor hypoxic regions may be an adverse prognostic factor in patients with breast cancer $(14,20)$; the results of the present study suggest that this may also apply to gastric cancer.

In a study by Reed et al (27), high rates of disease recurrence have been associated with the abundance of lymphatic channels and vascularization within the gastric wall, which may provide opportunity for cancer cells to migrate. Tie2 is a receptor involved in angiogenesis (19). The results of the present study demonstrated that the number of patients with Tie2-positive gastric cancer was increased alongside an increase in the rate of regional lymph node invasion, which is concordant with the observations of Reed et al (27).

Following surgery, the gastric cancer recurrence rate was increased in the Tie2-positive group and Tie2 protein expression was higher in hypoxic gastric cancer tissues compared with in normoxic gastric cancer tissues. The hypoxic microenvironment of a tumor serves two roles. Firstly, hypoxia may lead to tumor necrosis but the microenvironment surrounding the tumor necrosis also induces angiogenesis, thus promoting tumor progression and metastasis (28-33). A number of 
previous studies have established that TEM infiltration in the tumor tissue promotes tumor angiogenesis in the microenvironment and, therefore, contribute to tumor progression and the metastasis of tumor cells $(10,30,31,33,34)$. Furthermore, with the development of the tumor, the hypoxic state of the tumor microenvironment induces the macrophage phenotype to change from $\mathrm{M} 1$ to $\mathrm{M} 2$, resulting in an modification from immune surveillance and cytotoxicity to immune escape, which promotes tumor progression and metastasis (35). These previous studies support the results of the present study, demonstrating that Tie2-positive TAMs located in the stroma of gastric cancer have an affect on tumor recurrence and patient survival.

The present study has limitations. The sample size was small and from a single institution. In addition, a comprehensive panel of prognostic markers was not assessed. Further investigation is required to fully assess the role of Tie 2 in the prognosis of gastric cancer, including in vitro experiments using TEMs in hypoxic and normoxic environments.

In conclusion, Tie 2 positive expression (representing infiltrated TEMs) in gastric tumors may be associated with poorer survival. Tie2 has the potential to be used as a prognostic marker for gastric cancer and may be a novel therapeutic target.

\section{Acknowledgements}

The authors would like to thank Dr. Ariel Yang from the Abramson Family Cancer Research Institute, University of Pennsylvania (Philadelphia, USA) for his valuable help proofreading the present study and Dr. Dong Yi from the Department of Statistics, The Third Military Medical University (Chongquing, China) for assistance with the statistical methods.

\section{Funding}

This study was supported by the National Natural Science Foundation of China (grant no. 30901426).

\section{Availability of data and materials}

The datasets generated and analyzed in the present study are included in this published article.

\section{Authors' contributions}

WJY, YXH, XY, and XLF performed the research. YXH and PWY designed the research. WJY, YS, HLY, PY and HLD analyzed the data. WJY and YXH wrote the paper.

\section{Ethics approval and consent to participate}

The current study was approved by the Institutional Review Board of the Southwest Hospital, Third Military Medical University and written informed consent was obtained from all patients.

\section{Consent for publication}

Written informed consent was obtained from all patients.

\section{Competing interests}

The authors declare that they have no competing interests.

\section{References}

1. Kohler BA, Ward E, McCarthy BJ, Schymura MJ, Ries LA, Eheman C, Jemal A, Anderson RN, Ajani UA and Edwards BK: Annual report to the nation on the status of cancer, 1975-2007, featuring tumors of the brain and other nervous system. J Natl Cancer Inst 103: 714-736, 2011.

2. Bertuccio P, Chatenoud L, Levi F, Praud D, Ferlay J, Negri E, Malvezzi M and La Vecchia C: Recent patterns in gastric cancer: A global overview. Int J Cancer 125: 666-673, 2009.

3. Zhu H, Yang X, Zhang C, Zhu C, Tao G, Zhao L, Tang S, Shu Z, Cai J, Dai S, et al: Red and processed meat intake is associated with higher gastric cancer risk: A meta-analysis of epidemiological observational studies. PLoS One 8: e70955, 2013.

4. Doll R, Peto R, Boreham J and Sutherland I: Mortality from cancer in relation to smoking: 50 years observations on British doctors. Br J Cancer 92: 426-429, 2005.

5. Marrelli D, Morgagni P, de Manzoni G, Coniglio A, Marchet A, Saragoni L, Tiberio G and Roviello F; Italian Research Group for Gastric C (IRGGC): Prognostic value of the 7th AJCC/UICC TNM classification of noncardia gastric cancer: Analysis of a large series from specialized Western centers. Ann Surg 255: 486-491, 2012.

6. Wagner AD, Unverzagt S, Grothe W, Kleber G, Grothey A Haerting J and Fleig WE: Chemotherapy for advanced gastric cancer. Cochrane Database Syst Rev: CD004064, 2010.

7. Gertler R, Rosenberg R, Feith M, Schuster T and Friess H: Pouch vs. no pouch following total gastrectomy: Meta-analysis and systematic review. Am J Gastroenterol 104: 2838-2851, 2009.

8. Pollard JW: Tumour-educated macrophages promote tumour progression and metastasis. Nat Rev Cancer 4: 71-78, 2004.

9. Balkwill F, Charles KA and Mantovani A: Smoldering and polarized inflammation in the initiation and promotion of malignant disease. Cancer Cell 7: 211-217, 2005.

10. Lewis CE and Pollard JW: Distinct role of macrophages in different tumor microenvironments. Cancer Res 66: 605-612, 2006.

11. Noy R and Pollard JW: Tumor-associated macrophages: From mechanisms to therapy. Immunity 41: 49-61, 2014.

12. van Netten JP, George EJ, Ashmead BJ, Fletcher C, Thornton IG and Coy P: Macrophage-tumour cell associations in breast cancer. Lancet 342: 872-873, 1993.

13. Takanami I, Takeuchi K and Kodaira S: Tumor-associated macrophage infiltration in pulmonary adenocarcinoma: Association with angiogenesis and poor prognosis. Oncology 57: 138-142, 1999.

14. Tsutsui S, Yasuda K, Suzuki K, Tahara K, Higashi H and Era S: Macrophage infiltration and its prognostic implications in breast cancer: The relationship with VEGF expression and microvessel density. Oncol Rep 14: 425-431, 2005.

15. Arai F, Hirao A, Ohmura M, Sato H, Matsuoka S, Takubo K, Ito K, Koh GY and Suda T: Tie2/angiopoietin-1 signaling regulates hematopoietic stem cell quiescence in the bone marrow niche. Cell 118: 149-161, 2004.

16. De Palma M, Venneri MA, Galli R, Sergi Sergi L, Politi LS, Sampaolesi M and Naldini L: Tie2 identifies a hematopoietic lineage of proangiogenic monocytes required for tumor vessel formation and a mesenchymal population of pericyte progenitors. Cancer Cell 8: 211-226, 2005.

17. Venneri MA, De Palma M, Ponzoni M, Pucci F, Scielzo C, Zonari E, Mazzieri R, Doglioni C and Naldini L: Identification of proangiogenic TIE2-expressing monocytes (TEMs) in human peripheral blood and cancer. Blood 109: 5276-5285, 2007.

18. Bingle L, Brown NJ and Lewis CE: The role of tumour-associated macrophages in tumour progression: Implications for new anticancer therapies. J Pathol 196: 254-265, 2002.

19. Medrek C, Ponten F, Jirstrom K and Leandersson K: The presence of tumor associated macrophages in tumor stroma as a prognostic marker for breast cancer patients. BMC Cancer 12: 306, 2012.

20. Kübler K, Ayub TH, Weber SK, Zivanovic O, Abramian A Keyver-Paik MD, Mallmann MR, Kaiser C, Serçe NB, Kuhn W and Rudlowski C: Prognostic significance of tumor-associated macrophages in endometrial adenocarcinoma. Gynecol Oncol 135: 176-183, 2014. 
21. Greene FL, Page DL, Fleming ID, et al: AJCC cancer staging handbook. New York: Springer, 2001.

22. Ajani JA, Beaii-saab T, Yang G, et al: NCCN clinical practice guidelines in oncology[M]: gastric cancer, 2009.

23. Kaluz S, Kaluzova M and Stanbridge EJ: The role of extracellular signal-regulated protein kinase in transcriptional regulation of the hypoxia marker carbonic anhydrase IX. J Cell Biochem 97: 207-216, 2006.

24. Trastour C, Benizri E, Ettore F, Ramaioli A, Chamorey E, Pouysségur J and Berra E: HIF-1alpha and CA IX staining in invasive breast carcinomas: Prognosis and treatment outcome. Int J Cancer 120: 1451-1458, 2007.

25. Hussain SA, Ganesan R, Reynolds G, Gross L, Stevens A, Pastorek J, Murray PG, Perunovic B, Anwar MS, Billingham L, et al: Hypoxia-regulated carbonic anhydrase IX expression is associated with poor survival in patients with invasive breast cancer. Br J Cancer 96: 104-109, 2007.

26. Brahimi-Horn MC and Pouyssegur J: The hypoxia-inducible factor and tumor progression along the angiogenic pathway. Int Rev Cytol 242: 157-213, 2005.

27. Reed VK, Krishnan S, Mansfield PF, Bhosale PR, Kim M, Das P, Janjan NA, Delclos ME, Lowy AM, Feig BW, et al: Incidence, natural history, and patterns of locoregional recurrence in gastric cancer patients treated with preoperative chemoradiotherapy. Int J Radiat Oncol Biol Phys 71: 741-747, 2008.

28. Hu B and Cheng SY: Angiopoietin-2: Development of inhibitors for cancer therapy. Curr Oncol Rep 11: 111-116, 2009.
29. Etoh T, Inoue H, Tanaka S, Barnard GF, Kitano S and Mori M: Angiopoietin-2 is related to tumor angiogenesis in gastric carcinoma: Possible in vivo regulation via induction of proteases. Cancer Res 61: 2145-2153, 2001.

30. Murdoch C, Giannoudis A and Lewis CE: Mechanisms regulating the recruitment of macrophages into hypoxic areas of tumors and other ischemic tissues. Blood 104: 2224-2234, 2004.

31. Burke B, Giannoudis A, Corke KP, Gill D, Wells M, Ziegler-Heitbrock L and Lewis CE: Hypoxia-induced gene expression in human macrophages: Implications for ischemic tissues and hypoxia-regulated gene therapy. Am J Pathol 163: 1233-1243, 2003.

32. Bingle L, Lewis CE, Corke KP, Reed MW and Brown NJ: Macrophages promote angiogenesis in human breast tumour spheroids in vivo. Br J Cancer 94: 101-107, 2006.

33. Murdoch C, Tazzyman S, Webster S and Lewis CE: Expression of Tie-2 by human monocytes and their responses to angiopoietin-2. J Immunol 178: 7405-7411, 2007.

34. Lewis CE, De Palma M and Naldini L: Tie2-expressing monocytes and tumor angiogenesis: Regulation by hypoxia and angiopoietin-2. Cancer Res 67: 8429-8432, 2007.

35. Manzur M, Hamzah J and Ganss R: Modulation of the 'blood-tumor' barrier improves immunotherapy. Cell Cycle 7: 2452-2455, 2008. 